\title{
Effectiveness of Mindfulness-Based Cognitive Therapy for Improving Subjective and Eudaimonic Well-Being in Healthy Individuals: A Randomized Controlled Trial
}

\author{
Teppei Kosugi ${ }^{1,2}$, Akira Ninomiya ${ }^{1,3}$, Maki Nagaoka ${ }^{1,4}$, Zenta Hashimoto ${ }^{1}$, \\ Kyosuke Sawada ${ }^{1}$, Sunre Park ${ }^{5,6}$, Daisuke Fujisawa ${ }^{1,6,7}$, Masaru Mimura ${ }^{1,3}$ and \\ Mitsuhiro Sado ${ }^{1,3 *}$ \\ ${ }^{1}$ Department of Neuropsychiatry, Keio University School of Medicine, Tokyo, Japan, ${ }^{2}$ Department of Psychiatry, Gunma \\ Hospital, Takasaki, Japan, ${ }^{3}$ Center for Stress Research, Keio University, Tokyo, Japan, ${ }^{4}$ Research Center for Child Mental \\ Development, Chiba University, Chiba, Japan, ${ }^{5}$ Faculty of Nursing and Medicine Care, Keio University, Tokyo, Japan, \\ ${ }^{6}$ Palliative Care Center, Keio University Hospital, Tokyo, Japan, ${ }^{7}$ Division of Patient Safety, Keio University Hospital, Tokyo, \\ Japan
}

\section{OPEN ACCESS}

Edited by:

Margarida Pocinho,

University of Madeira, Portugal

Reviewed by:

Cristián Coo Calcagni,

University of Jaume I, Spain

Sayo Hamatani,

Chiba University, Japan

*Correspondence:

Mitsuhiro Sado

mitsusado@keio.jp

Specialty section:

This article was submitted to

Positive Psychology,

a section of the journal

Frontiers in Psychology

Received: 27 April 2021 Accepted: 03 August 2021

Published: 27 August 2021

Citation:

Kosugi T, Ninomiya A, Nagaoka M,

Hashimoto Z, Sawada K, Park S,

Fujisawa D, Mimura $M$ and Sado $M$

(2021) Effectiveness of

Mindfulness-Based Cognitive Therapy

for Improving Subjective and

Eudaimonic Well-Being in Healthy

Individuals: A Randomized Controlled

Trial. Front. Psychol. 12:700916.

doi: 10.3389/fpsyg.2021.700916
Objectives: Better subjective and eudaimonic well-being fosters better health conditions. Several studies have confirmed that mindfulness-based interventions are effective for improving well-being; however, the samples examined in these studies have been limited to specific populations, and the studies only measured certain aspects of well-being rather than the entire construct. Additionally, few studies have examined the effect of mindfulness-based cognitive therapy on well-being. The present study examines the feasibility of mindfulness-based cognitive therapy and its effectiveness for improving subjective and eudaimonic well-being among community residents.

Methods: The study design featured an 8-week randomized, waiting-list controlled, parallel-group study. 8 weekly mindfulness classes, followed by 2 monthly classes, were provided for healthy individuals aged 20-65 years who had a Satisfaction with Life Scale score of $\leq 24$ indicating average to low cognitive aspect of subjective well-being. This trial was registered with the University Hospital Medical Information Network Clinical Trials Registry (ID: UMIN000031885, URL: https://upload.umin.ac.jp/cgi-open-bin/ctr_e/ctr_ view.cgi?recptno=R000036376).

Results: The results showed that cognitive aspect of subjective well-being and mindfulness skills were significantly improved at 8 weeks, and this effect was enhanced up to the end of the follow-up period. Positive affective aspect of subjective and eudaimonic well-being were significantly improved at 16 weeks.

Conclusions: Eight weeks of mindfulness-based cognitive therapy with a 2-month follow-up period improves cognitive and affective aspects of subjective and eudaimonic well-being in healthy individuals. The order of improvement was cognitive, positive affective, and eudaimonic well-being. To verify these findings, multi-center randomized controlled trials with active control groups and longer follow-up periods are warranted.

Keywords: subjective well-being, mindfulness, mindfulness based cognitive therapy, healthy volunteers, quality of life, resilience, happiness, eudaimonic well-being 


\section{INTRODUCTION}

Research on well-being has been gaining increasing academic attention recently. (Ryff, 2014; Diener et al., 2018). In this field, subjective well-being (SWB) and eudaimonic well-being are the two dominant concepts (Keyes et al., 2002; Ryff, 2014; Diener et al., 2018), which differ in the way they approach well-being (Keyes et al., 2002). SWB represents a global assessment of how a person evaluates his or her own life and experiences (Diener, 1984). Two aspects of SWB have been identified, namely, life evaluation, and affect (OECD, 2013; Diener et al., 2018). Life evaluation relates to the cognitive aspect of SWB, and represents a person's satisfaction with their life (Diener et al., 1985). The affective aspect of SWB relates to the experience of both positive and negative emotions (OECD, 2013). Eudaimonic well-being is a type of well-being that has been discussed in humanistic, existential, developmental, and clinical psychology since the philosophy of Aristotle in ancient Greece, which represents a person's level of functioning and realization of their potential (Keyes et al., 2002; Huppert et al., 2009; OECD, 2013; Ryff, 2014). The cognitive and affective aspects of SWB and eudaimonic wellbeing are mildly correlated, but are clearly distinguishable from one another (Keyes et al., 2002; OECD, 2013; Diener et al., 2018). When measuring an individual's well-being, taking into account both SWB and eudaimonic well-being can provide a comprehensive snapshot of their well-being (OECD, 2013).

Better status in each type of well-being contributes to better health (Diener et al., 2018), including lower stress (Diener et al., 2017), higher resilience (Diener et al., 2018), and longer life expectancy (Howell et al., 2007; Diener and Chan, 2011; Steptoe et al., 2015). Therefore, from a public health perspective, developing intervention methods to improve the well-being of the general public is very important.

Some interventions, such as keeping positive events diaries (Burton and King, 2004; Lyubomirsky et al., 2011), expressing gratitude (Lyubomirsky et al., 2011), and performing acts of kindness (Buchanan and Bardi, 2010) are effective for improving well-being in both clinical and non-clinical settings (Bolier et al., 2013). In addition, mindfulness-based interventions (MBIs) have shown potential to improve well-being among the general public.

Although the original target of MBIs was clinical populations such as people with depression (Teasdale et al., 2000), anxiety disorders (Hoge et al., 2013), patients with cancer who were experiencing psychological distress (Foley et al., 2010), and people experiencing chronic pain (Khoury et al., 2013), MBIs have also been applied outside of the medical field, including to healthy populations, targeting stress management or well-being improvement. Mindfulness-to-meaning theory is one theory that explains the mechanism of the effects of mindfulness on well-being. According to this theory, the improvement of metacognitive awareness through mindfulness training promotes a positive reappraisal of experiences. As a result, the increasing positivity creates a sense of meaning in life, which enhances eudaimonic well-being (Garland et al., 2015). Several other studies have also confirmed that MBIs are effective for mitigating stress and improving well-being (Shapiro et al., 1998, 2005, 2011; Cohen-Katz et al., 2005; Jain et al., 2007; Carmody and Baer, 2008;
Vieten and Astin, 2008; Klatt et al., 2009; Robins et al., 2012; de Vibe et al., 2013; Flook et al., 2013; Malarkey et al., 2013; Nyklicek et al., 2013; Huang et al., 2015; Song and Lindquist, 2015; Ivtzan et al., 2016, 2018; van Dongen et al., 2016; Bartlett et al., 2017; Chu and Mak, 2020).

However, there are some limitations to the above findings. First, they targeted specific populations such as students (Shapiro et al., 1998, 2011; Jain et al., 2007; de Vibe et al., 2013; Song and Lindquist, 2015), school teachers (Klatt et al., 2009; Flook et al., 2013), health-care workers (Cohen-Katz et al., 2005; Shapiro et al., 2005), and employees in their workplaces (Malarkey et al., 2013; Huang et al., 2015; van Dongen et al., 2016; Bartlett et al., 2017). It is therefore difficult to generalize these results to the community. Second, neither of the two studies (Robins et al., 2012; Nyklicek et al., 2013) that targeted healthy people in the community assessed both SWB and eudaimonic well-being simultaneously. Consequently, it is unclear how MBIs affect each aspect of these well-beings. Finally, despite the confirmed effects of mindfulness-based stress reduction (MBSR) on wellbeing (Khoury et al., 2015), the evidence of mindfulness-based cognitive therapy (MBCT), another major MBI (Segal et al., 2002), on well-being is sparse. Considering these limitations, our study aims to perform a randomized controlled trial (RCT) to assess the feasibility and effectiveness of MBCT in improving the cognitive and affective aspects of subjective and eudaimonic wellbeing among healthy people enrolled from a community sample. The economic evaluation will be reported separately.

\section{MATERIALS AND METHODS}

This study was performed at Keio University Hospital, Tokyo, Japan. The study protocol is published (Sado et al., 2020) and was registered in the University Hospital Medical Information Network Clinical Trials Registry (UMIN000031885; https:// upload.umin.ac.jp/cgi-open-bin/ctr_e/ctr_view.cgi?recptno= R000036376) and was performed and reported according to CONSORT guidelines.

\section{Participants}

Participants were recruited through the Center for Stress Research at Keio University (Keio CSR). Eligibility criteria were healthy individuals who (1) were aged 20-65 years, (2) had no history of psychiatric disorder in the past 2 years, (3) scored $\leq 24$ on the Satisfaction With Life Scale (SWLS) (Diener et al., 1985) indicating average to low cognitive aspect of subjective well-being (Oishi, 2009), and (4) were able to complete a consent form.

The exclusion criteria were (1) being likely to be difficult to follow up, (2) previous engagement in MBIs similar to that administered in this study, and (3) having a severe physical illness.

\section{Enrollment}

Participants applied through a form presented on Keio CSR's website and answered online screening questionnaires (first screening). Each participant who passed the first screening was then interviewed by a psychiatrist or psychologist from the study team (second screening) to confirm whether they satisfied the 
eligibility criteria. For diagnostic assessment, participants were screened using the Japanese version of the Structured Clinical Interview for DSM-IV Axis I Disorders (American Psychiatric Association, 2000). Participants were enrolled according to the results of the second screening. Eligible participants were given detailed explanations of the study procedures, after which they provided written informed consent.

\section{Baseline Assessment}

A battery of questionnaires was used to collect demographic and psychosocial data from the eligible participants. Details of the psychological measures are provided below.

\section{Randomization and Masking}

All enrolled participants were randomly assigned 1:1 to the MBCT group or the waiting list control group (control group) with masking for researchers and participants. Assignment was performed using a computer-generated random number system that was administered independently of the present authors by the Keio Center of Clinical Research Project Management Office.
Randomization was stratified using the participants' baseline scores for the SWLS $(\geq 20, \leq 19)$. The nature of the psychological intervention in question meant that the allocation group of the participants and intervention instructors could not be blinded. As all outcome instruments utilized were self-reported, participants were not assessed by anyone.

\section{Interventions MBCT Group}

The intervention program comprised a modified version of MBCT, and was based on the guide developed by Williams and Penman (2011). MBI programs need to be based on MBCT and MBSR, and adjusted appropriately for the target of intervention (Crane et al., 2017). As the MBCT was originally developed for patients with depression (Teasdale et al., 2000), for the present study, we modified the MBCT program to focus on improving well-being of a non-clinical population. The contents of the program are shown in Table 1. The main differences between our program and the original MBCT were as follows: (1) a psychoeducational lecture concerning depression was

TABLE 1 | Contents of the program.

\begin{tabular}{|c|c|c|}
\hline Session & Theme & Contents \\
\hline \multirow[t]{3}{*}{1} & Waking up to the automatic pilot & Psychoeducation: What is mindfulness? \\
\hline & & $\begin{array}{l}\text { Exercise: Mindfulness eating ('raisin exercise')/asking yourself why you are here now/mindfulness of } \\
\text { body and breath }\end{array}$ \\
\hline & & Homework: Mindfulness of body and breath/mindfulness of a routine activity/Let go of habits \\
\hline \multirow[t]{3}{*}{2} & Keeping the body in mind & Psychoeducation: Association of mood and thoughts \\
\hline & & Exercise: Mindfulness of body and breath/ Thoughts and feelings exercise/Body scan \\
\hline & & Homework: Body scan/pleasant event calendar/mindfulness in everyday life/Let go of habits \\
\hline \multirow[t]{3}{*}{3} & The mouse in the maze & Psychoeducation: Awareness of mind wandering and focusing on the breath \\
\hline & & Exercise: Breathing meditation/meditation of sounds/gentle yoga/mindful walking \\
\hline & & $\begin{array}{l}\text { Homework: Three-minute breathing space/gentle yoga/mindful walking/Diary of appreciation and } \\
\text { gratitude events/let go of habits }\end{array}$ \\
\hline \multirow[t]{3}{*}{4} & Moving beyond the rumor mill & Psychoeducation: Staying present \\
\hline & & Exercise: Mindfulness meditations (breathing/sounds and thoughts) \\
\hline & & $\begin{array}{l}\text { Homework: Mindfulness meditations (breathing/sounds and thoughts/three-minute breathing } \\
\text { space)/Unpleasant events calendar/Let go of habits }\end{array}$ \\
\hline \multirow[t]{3}{*}{5} & Turning toward difficulties & Psychoeducation: Exploring difficulty \\
\hline & & Exercise: Mindfulness meditations (breathing/sounds and thoughts/exploring difficulty) \\
\hline & & $\begin{array}{l}\text { Homework: Mindfulness meditations (breathing/sounds and thoughts/exploring difficulty/three-minute } \\
\text { breathing space)/Let go of habits }\end{array}$ \\
\hline \multirow[t]{3}{*}{6} & Trapped in the past or living in the present & Psychoeducation: Cognitive biases/Compassion for myself \\
\hline & & $\begin{array}{l}\text { Exercise: Mindfulness meditations/compassion meditation/watching the movie "Happy" about } \\
\text { well-being. }\end{array}$ \\
\hline & & $\begin{array}{l}\text { Homework: Mindfulness meditations (sounds and thoughts/exploring difficulty/compassion/three-minute } \\
\text { breathing space)/diary of your kind behaviour }\end{array}$ \\
\hline \multirow[t]{3}{*}{7} & When did you stop dancing & Psychoeducation: Choosing functional behaviours/behavioural activation/identifying triggers \\
\hline & & Exercise: Mindfulness meditations (breathing/sounds and thoughts) \\
\hline & & $\begin{array}{l}\text { Homework: Mindfulness meditations (choose what you like/three-minute breathing space)/diary of } \\
\text { activity that nourishes }\end{array}$ \\
\hline \multirow[t]{2}{*}{8} & Your wild and precious life & $\begin{array}{l}\text { Psychoeducation: Personal reflections of course/plans for future practice and strategies for maintaining } \\
\text { momentum/farewell }\end{array}$ \\
\hline & & Exercise: Body scan/asking yourself why you are here now and what you realised through the program \\
\hline
\end{tabular}


omitted from our program, and (2) compassion meditation and activity records (pleasant, unpleasant, appreciation events, and nourishing and depriving activities) were added to the program. Through the program, participants experienced mindfulness practices (e.g., the raisin exercise, body scan, sitting meditation, mindful walking, and three-step breathing space) and learned cognitive approaches.

Eight 2-h sessions, administered once a week, were implemented in the program. Each session was conducted in groups (of up to 15 participants). Once these eight sessions were completed, two booster sessions, once a month, were provided during a 2-month follow-up period. During the initial 8 -week period, participants were given daily homework in which they performed mindfulness meditation for $30-60 \mathrm{~min}$. No homework was assigned during the follow-up period. Instead, participants were asked to submit a short essay each month regarding their daily practice to share their experiences with the other group members.

\section{Control Group}

During the intervention period, no interventions were provided for the participants on the waiting list. These participants were instructed not to participate in other mindfulness or meditation activities during this period. Once the intervention period had ended, the control group was given opportunities to participate in the MBCT program.

\section{Outcomes}

\section{Primary Outcome}

The primary outcome was the difference between the MBCT group and control group regarding their respective mean change scores for SWLS from the baseline evaluation to the postintervention evaluation.

\section{Secondary Outcomes}

The secondary outcomes were the differences between the $\mathrm{MBCT}$ group and control group regarding their respective mean change scores (again from the baseline to the post-intervention assessment) for the variables measured using the instruments listed in the following section.

\section{Instruments \\ Satisfaction With Life Scale}

The SWLS is a self-reported questionnaire that assesses life satisfaction through five questions. Total score is in the range of 5 to 35 , and higher scores represent increased cognitive aspect of subjective well-being (Diener et al., 1985).

\section{Flourishing Scale}

The Flourishing Scale (FS) comprises eight items measuring factors that represent the social-psychological well-being linked to eudaimonic well-being to complement existing measures of SWB. It can measure well-being in eight dimensions that

TABLE 2 | Schedule of assessments.

\begin{tabular}{|c|c|c|c|c|c|c|c|c|c|c|c|c|c|}
\hline & \multicolumn{2}{|c|}{ Screening } & \multicolumn{11}{|c|}{ Week } \\
\hline Screening (web) & 0 & & & & & & & & & & & & \\
\hline $\begin{array}{l}\text { Screening (face to } \\
\text { face interview) }\end{array}$ & & 0 & & & & & & & & & & & \\
\hline Informed consent & & & 0 & & & & & & & & & & \\
\hline SCID & & $\bigcirc$ & & & & & & & & & & & \\
\hline Demographics & 0 & & $\bigcirc$ & & & & & & & & & & \\
\hline SWLS & & & $\bigcirc$ & & & & 0 & & & & $\bigcirc$ & & 0 \\
\hline FS & & & $\bigcirc$ & & & & $\bigcirc$ & & & & 0 & & $\bigcirc$ \\
\hline SPANE & & & 0 & & & & 0 & & & & 0 & & 0 \\
\hline RSES & & & 0 & & & & 0 & & & & 0 & & 0 \\
\hline GAD7 & & & $\bigcirc$ & & & & 0 & & & & $\bigcirc$ & & 0 \\
\hline PSS & & & $\bigcirc$ & & & & 0 & & & & 0 & & 0 \\
\hline WHO-HPQ & & & 0 & & & & 0 & & & & 0 & & 0 \\
\hline MAIA & & & $\bigcirc$ & & & & 0 & & & & $\bigcirc$ & & 0 \\
\hline EQ-5D-5L & & & 0 & & & & 0 & & & & 0 & & 0 \\
\hline
\end{tabular}

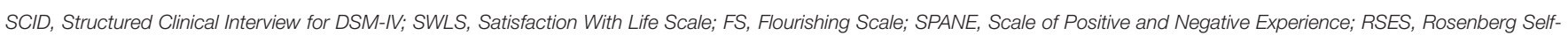

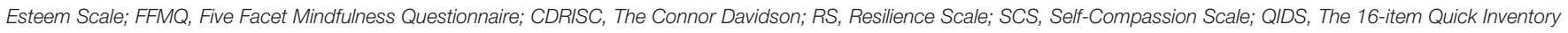

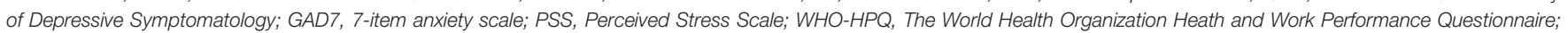

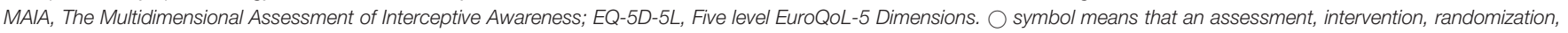
informed consent, or interview was conducted at that time. 
are based on existing theories plus recent theories related to psychological and social well-being. Total score is in the range of 8 to 56. Higher scores indicate higher eudaimonic well-being (Diener et al., 2010).

\section{Scale of Positive and Negative Experience}

The Scale of Positive and Negative Experience (SPANE) is a 12item scale (six items assess positive experiences and six assess negative experiences) that measures the affective aspect of SWB. The scale evaluates the whole range of positive and negative experiences with specific feelings. The positive and negative scales are scored separately because the two types of emotions are partially independent or separable. The positive score (SPANE$\mathrm{P}$ ) and the negative scale (SPANE-N) are in the range of 6 to 30. Higher scores represent higher positive or negative affective aspects of SWB. Subtracting the negative score from the positive score represents the SPANE-B score that ranges from -24 to 24 (Diener et al., 2010).

\section{Rosenberg Self-Esteem Scale}

The Rosenberg Self-Esteem Scale (RSES) is a self-administered rating scale that assesses self-esteem. Total score is in the range of 10 to 40 . Higher scores indicate higher self-esteem (Rosenberg, 1965).

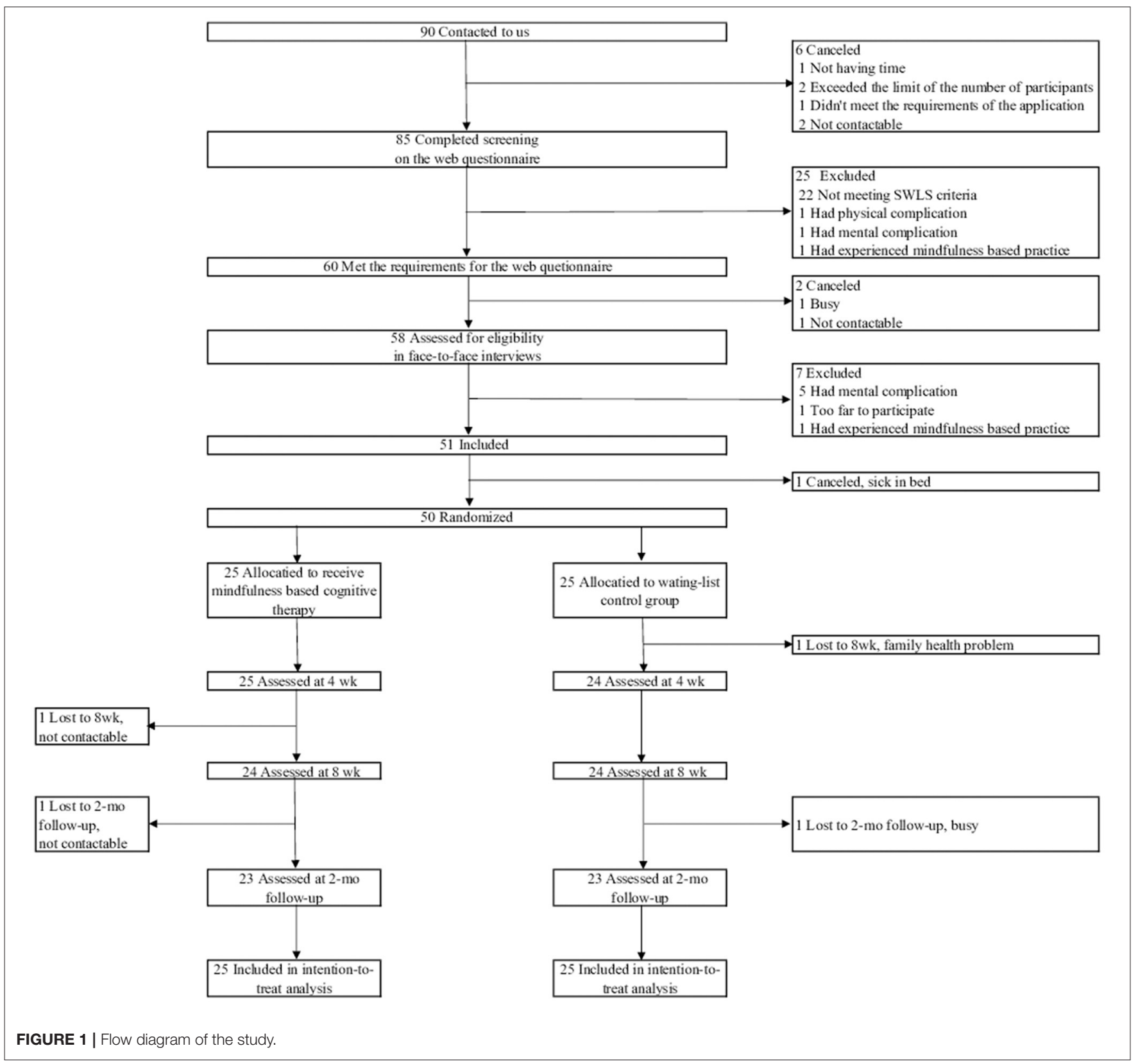




\section{Five Facet Mindfulness Questionnaire}

The Five Facet Mindfulness Questionnaire (FFMQ) is a selfreported questionnaire that assesses mindfulness abilities. The five facets are observing, describing, acting with awareness, non-judging, and non-reacting. Higher scores indicate higher mindfulness abilities (Baer et al., 2006).

\section{Connor Davidson Resilience Scale}

The Connor Davidson Resilience Scale (CDRISC) is a selfreported scale measuring resilience over the past month. Total score is in the range of 0 to 100 , with higher scores indicating greater resilience (Connor and Davidson, 2003).

\section{Self-Compassion Scale}

The Self-Compassion Scale (SCS) measures a person's ability to understand themself with kindness, rather than being harsh or self-critical of their pain and failure. It comprises 29 items and six subscales (self-kindness, self-judgment, common humanity, isolation, mindfulness, and over-identification); scores for each subscale range from 1 to 5 and are calculated from the average score of each component. The sum of the subscales is the total

TABLE 3 | Baseline sociodemographic characteristics.

\begin{tabular}{|c|c|c|c|c|c|c|c|}
\hline \multirow{2}{*}{$\begin{array}{l}\text { Sociodemographic } \\
\text { characteristics }\end{array}$} & \multicolumn{2}{|c|}{$\begin{array}{c}\text { Total } \\
(n=50)\end{array}$} & \multicolumn{2}{|c|}{$\begin{array}{c}\text { MBCT } \\
(n=25)\end{array}$} & \multicolumn{2}{|c|}{$\begin{array}{l}\text { Control } \\
(n=25)\end{array}$} & \multirow{2}{*}{$\begin{array}{c}\text { Statistics } \\
0.39^{\mathrm{a}}\end{array}$} \\
\hline & 46.8 & $(8.7)$ & 47.8 & $(9.6)$ & 45.7 & $(7.8)$ & \\
\hline Sex (female), $n(\%)$ & 39 & (78.0) & 20 & $(80.0)$ & 19.0 & (76.0) & $0.73^{\mathrm{a}}$ \\
\hline Education, $n(\%)$ & & & & & & & $0.44^{b}$ \\
\hline High school & 3 & $(6.0)$ & 2 & $(8.0)$ & 1 & $(4.0)$ & \\
\hline Junior college/vocational school & 12 & $(24.0)$ & 4 & $(16.0)$ & 8 & (32.0) & \\
\hline University & 22 & $(44.0)$ & 13 & $(52.0)$ & 9 & $(36.0)$ & \\
\hline Graduate school & 12 & $(24.0)$ & 5 & $(20.0)$ & 7 & $(28.0)$ & \\
\hline Unclear & 1 & $(2.0)$ & 1 & $(4.0)$ & 0 & $(0.0)$ & \\
\hline Job, $n(\%)$ & & & & & & & $0.51^{\mathrm{b}}$ \\
\hline President/exective & 6 & $(12.0)$ & 1 & $(4.0)$ & 5 & $(20.0)$ & \\
\hline Office worker & 16 & $(32.0)$ & 6 & $(24.0)$ & 10 & $(40.0)$ & \\
\hline Civil servant & 3 & $(6.0)$ & 2 & $(8.0)$ & 1 & $(4.0)$ & \\
\hline Self-employed & 7 & $(14.0)$ & 5 & $(20.0)$ & 2 & $(8.0)$ & \\
\hline Freelancer & 1 & $(2.0)$ & 1 & $(4.0)$ & 0 & $(0.0)$ & \\
\hline Profession & 6 & $(12.0)$ & 3 & $(12.0)$ & 3 & $(12.0)$ & \\
\hline Part-time worker & 4 & $(8.0)$ & 2 & $(8.0)$ & 2 & $(8.0)$ & \\
\hline Student & 2 & $(4.0)$ & 1 & $(4.0)$ & 1 & $(4.0)$ & \\
\hline Homemaker & 4 & $(8.0)$ & 3 & (12.0) & 1 & $(4.0)$ & \\
\hline Others & 1 & $(2.0)$ & 1 & $(4.0)$ & 0 & $(0.0)$ & \\
\hline Marital status, $n(\%)$ & & & & & & & $0.79^{b}$ \\
\hline Married & 30 & $(60.0)$ & 15 & $(60.0)$ & 15 & $(60.0)$ & \\
\hline Single & 15 & $(30.0)$ & 7 & $(28.0)$ & 8 & (32.0) & \\
\hline Separated, divorced, & 4 & $(8.0)$ & 2 & $(8.0)$ & 2 & $(8.0)$ & \\
\hline Widowed & 1 & $(2.0)$ & 1 & $(4.0)$ & 0 & $(0.0)$ & \\
\hline Cohabiting, $n(\%)$ & 35 & $(70.0)$ & 17 & $(68.0)$ & 18 & $(72.0)$ & $0.76^{a}$ \\
\hline Physical complications, $n$ (\%) & 8 & $(16.0)$ & 3 & $(12.0)$ & 5 & $(20.0)$ & $0.44^{\mathrm{a}}$ \\
\hline Household income (yen), n (\%) & & & & & & & $0.97^{b}$ \\
\hline$<2,000,000$ & 1 & $(2.0)$ & 1 & $(4.0)$ & 0 & $(0.0)$ & \\
\hline $2,000,000 \leq, 4,000,000<$ & 2 & $(4.0)$ & 1 & $(4.0)$ & 1 & $(4.0)$ & \\
\hline $4,000,000 \leq, 6,000,000<$ & 9 & $(18.0)$ & 5 & $(20.0)$ & 4 & $(16.0)$ & \\
\hline $6,000,000 \leq, 8,000,000<$ & 6 & $(12.0)$ & 3 & $(12.0)$ & 3 & $(12.0)$ & \\
\hline $8,000,000 \leq, 10,000,000<$ & 7 & $(14.0)$ & 3 & $(12.0)$ & 4 & $(16.0)$ & \\
\hline $10,000,000 \leq, 12,000,000<$ & 7 & $(14.0)$ & 3 & $(12.0)$ & 4 & $(16.0)$ & \\
\hline $12,000,000 \leq$ & 18 & $(36.0)$ & 9 & $(36.0)$ & 9 & $(36.0)$ & \\
\hline Income (yen), $n$ (\%) & & & & & & & $0.67^{b}$ \\
\hline$<2,000,000$ & 11 & $(22.0)$ & 8 & $(32.0)$ & 3 & $(12.0)$ & \\
\hline $2,000,000 \leq, 4,000,000<$ & 8 & $(16.0)$ & 4 & $(16.0)$ & 4 & $(16.0)$ & \\
\hline $4,000,000 \leq, 6,000,000<$ & 11 & $(22.0)$ & 4 & $(16.0)$ & 7 & $(28.0)$ & \\
\hline $6,000,000 \leq, 8,000,000<$ & 9 & $(18.0)$ & 5 & $(20.0)$ & 4 & $(16.0)$ & \\
\hline $8,000,000 \leq, 10,000,000<$ & 3 & $(6.0)$ & 1 & $(4.0)$ & 2 & $(8.0)$ & \\
\hline $10,000,000 \leq, 12,000,000<$ & 3 & $(6.0)$ & 1 & $(4.0)$ & 2 & $(8.0)$ & \\
\hline $12,000,000 \leq$ & 5 & $(10.0)$ & 2 & $(8.0)$ & 3 & $(12.0)$ & \\
\hline
\end{tabular}

a Student's t-test.

${ }^{b}$ Chi-square test. 
SCS scale score. Its range is from 5 to 30, with higher scores indicating more self-compassion (Neff, 2003).

\section{6-Item Quick Inventory of Depressive Symptomatology}

The 16-item Quick Inventory of Depressive Symptomatology (QIDS) is a self-reported questionnaire that assesses depressive symptoms. The total score is in the range of 0 to 27 . Higher scores represent increased depression (Rush et al., 2003).

\section{General Anxiety Disorder-7}

The General Anxiety Disorder-7 (GAD-7) examines anxiety symptoms experienced during the previous 2 weeks. Total score is in the range of 0 to 21 . Higher scores represent higher levels of anxiety symptoms (Spitzer et al., 2006).

\section{Perceived Stress Scale}

The Perceived Stress Scale (PSS) evaluates stress regarding one's life conditions over the previous month. Total score is in the range of 0 to 40 . Higher scores indicate higher stress levels (Cohen et al., 1983).

\section{World Health Organization Health and Work Performance Questionnaire}

The World Health Organization Health and Work Performance Questionnaire (WHO-HPQ) is a self-reported scale that evaluates the workplace costs of health issues relating to loss of job performance (presenteeism). The scale has two items, one to assess one's own work performance and the other to assess how well one's colleagues are performing at work. Both items have a range of 0 to 10 . Absolute presenteeism is a ten-fold increase in the former item's score (range from 0 to 100). Relative presenteeism is the score of the former divided by the score of

\begin{tabular}{|c|c|c|c|c|c|c|c|}
\hline SWLS & 18.5 & 4.3 & 18.7 & 4.2 & 18.3 & 4.5 & 0.75 \\
\hline FS & 39.0 & 6.0 & 40.6 & 5.1 & 37.5 & 6.5 & 0.06 \\
\hline SPANE-N & 15.8 & 4.0 & 17.0 & 3.6 & 18.6 & 2.9 & 0.09 \\
\hline SPANE-B & 2.3 & 5.0 & 4.3 & 5.4 & 0.20 & 3.6 & 0.00 \\
\hline FFMQ total ${ }^{b}$ & 118.3 & 14.3 & 119.8 & 13.1 & 116.7 & 15.5 & 0.45 \\
\hline \multicolumn{8}{|l|}{ MAIA } \\
\hline Noticing & 2.7 & 0.90 & 2.8 & 0.98 & 2.7 & 0.84 & 0.59 \\
\hline Not-distracting & 2.6 & 1.0 & 2.4 & 0.91 & 2.8 & 1.1 & 0.16 \\
\hline Self-Regulation & 2.8 & 0.81 & 2.9 & 0.76 & 2.7 & 0.86 & 0.39 \\
\hline Body listening & 2.0 & 1.2 & 2.2 & 0.99 & 1.8 & 1.3 & 0.19 \\
\hline Trusting & 2.4 & 0.94 & 2.6 & 0.90 & 2.2 & 0.93 & 0.09 \\
\hline RSES & 23.8 & 3.6 & 23.2 & 3.6 & 24.3 & 3.6 & 0.68 \\
\hline CDRISC & 59.0 & 14.1 & 62.6 & 13.1 & 55.4 & 14.4 & 0.07 \\
\hline SCS total & 17.6 & 3.3 & 18.2 & 2.9 & 17.0 & 3.6 & 0.21 \\
\hline $\mathrm{PSS}^{b}$ & 17.8 & 4.1 & 16.8 & 3.9 & 18.8 & 4.1 & 0.08 \\
\hline GAD7 & 4.3 & 3.1 & 4.2 & 3.4 & 4.3 & 2.9 & 0.93 \\
\hline QIDS & 3.8 & 3.0 & 3.6 & 2.5 & 4.0 & 3.5 & 0.68 \\
\hline EQ-5D-5L utility & 0.90 & 0.11 & 0.92 & 0.11 & 0.88 & 0.11 & 0.81 \\
\hline
\end{tabular}

\footnotetext{
a Student's t-test.

${ }^{b}$ Total number decreased in the Control group $(n=25 \rightarrow 24$, FFMQ, PSS) because of missing value.

${ }^{c}$ Exclude those not working; results for 48 in total, 25 in the MBCT group and 23 in the Control group.

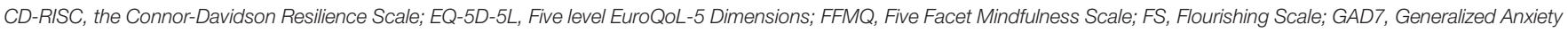

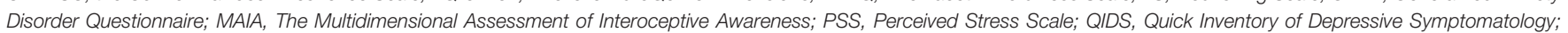

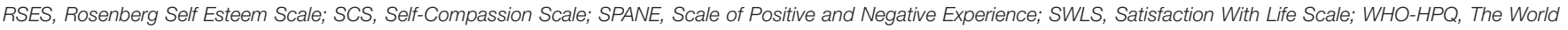
Health Organization Heath and Work Performance Questionnaire.
} 
the latter (range from 0.25 to 2.0). Higher scores indicate a higher rating for work performance (Kessler et al., 2003).

\section{Multidimensional Assessment of Interceptive Awareness}

Interceptive awareness is known to be a vital element in meditation and stress reduction (Bornemann et al., 2015) The Multidimensional Assessment of Interceptive Awareness (MAIA) is a 32-item instrument that assesses interceptive awareness using the following eight dimensions: noticing, not-distracting, not-worrying, attention regulation, emotional awareness, self- regulation, body listening, and trusting. Total scores for each dimension are in the range of 0 to 5 (Mehling et al., 2012).

\section{EuroQoL-5 Dimensions 5-Level}

The EuroQoL-5 Dimensions 5-level (EQ-5D-5L) measures health outcomes and quality of life. It is a five-item questionnaire that focuses on health-related quality of life. Total score is in the range of 0 to 1 (Herdman et al., 2011).

\section{Instrument Reliability and Validity}

The reliability and validity of all of the above instruments have been proven for Japanese populations (Kadono, 1994; Hamashima and Yoshida, 2001; Tsuchiya et al., 2002; Mimura and Griffiths, 2007, 2008; Ito et al., 2009; Muramatsu et al., 2009, 2010; Fujisawa et al., 2010; Sugiura et al., 2011; Arimitsu, 2014; Sumi, 2014; Doi et al., 2018; Shoji et al., 2018; Kawakami et al., 2020).

\section{Schedule of Visits and Assessments}

All participants completed these instruments at baseline, 4, 8 weeks, and at the end of the follow-up. The schedule of assessment is shown in Table 2.

\section{Sample Size}

We conducted a pilot study (unpublished) to explore the feasibility, safety, and effectiveness of MBCT for improving wellbeing before this study. The pilot study showed that the mean SWLS score had a pre/post difference of $3.1(\mathrm{SD}=3.4)$. Based on the results, a sample size calculation was performed to obtain a statistical power of at least $80 \%$ and a significance level of $5 \%$ (two-sided), and it was determined that 20 participants were required in each group. Estimating a dropout rate of 20\%, 25 participants in each arm were needed (50 participants in total).

\section{Statistical Analysis}

To compare the two groups' baseline demographic and clinical characteristics, unpaired $t$-tests were adopted for the continuous variables and chi-square tests for the categorical variables. The primary and secondary outcomes were analyzed using an intention-to-treat approach, and a mixed-effects model repeat measurement was used to control for dropouts. A fixed-effects model was used for the intervention group, week, and group-byweek interaction, age, and sex. A 5\% significance level was used for all statistical analyses. Stata Version 14 software (StataCorp LLC, College Station, TX, USA) was adopted to perform the statistical analyses. For well-being outcomes (i.e., SWLS, FS, and
SPANE), the effect size was calculated dividing the difference between groups by its standard deviation.

\section{RESULTS}

The flow of the study from screening to post intervention is shown in Figure 1. This study began recruiting participants in July 2018 and final data collection was completed in December 2019. Dataset construction was completed at the end of March 2020. Beginning in July 2018, 90 participants were screened. Fifty participants $(55.6 \%)$ met the inclusion criteria and were randomly allocated to the MBCT group $(n=25)$ or the waitinglist control group $(n=25)$. Two participants in each group dropped out. The participants' baseline demographic and clinical characteristics are shown in Tables 3, 4. The average age was $46.8 \pm 8.7$ years, and $78.0 \%$ were female. All participants were employed or were students or homemakers, and the average household income was relatively high. No significant differences between the groups were observed with respect to sociodemographic status. In terms of the clinical measures, there were no significant differences, except for SPANE-P, SPANE-B and MAIA Not-Worrying.

Treatment engagement is shown in Table 5. Average attendance of the 8 -week session was $7.08 \pm 1.58$ classes. Fourteen $(56.0 \%)$ participants completed the 8 -week session. The average attendance of the 8 weekly sessions plus the two followup classes was $8.76 \pm 2.05$ classes. No serious adverse events were observed over the study period. Total mean homework time during the 8-week session was $1202.2 \pm 455.5 \mathrm{~min}$.

\section{Primary Outcome}

Differences between the MBCT group and the control group regarding mean change scores for SWLS scores (effect size: 0.47; difference: 2.79 ; 95\% confidence interval [CI]: 0.39-5.20; $P=$ 0.023 ) were significant at 8 weeks (Table 6). The MBCT's effect was even stronger at the 2-month follow-up (effect size: 0.55; difference: 3.38 ; 95\% CI: 0.94-5.81; $P=0.007)$.

\section{Secondary Outcomes}

Scores for the FS and SPANE-P (which represented positive affect) showed significant improvement at the 2-month followup (Table 6). There was a significant improvement in total FFMQ, SCS and PSS score at 8 weeks, and in CDRISC scores

\section{TABLE 5 | Treatment engagement.}

Variable

$\operatorname{MBCT}(n=25)$

8 week session, $n$ (SD) (Weekly,

range: 0-8)

Completion rate of the full course of

MBCT sessions (8 week), $n$ (\%)

Follow up session, $n$ (SD) (Monthly,

range: 0-2 sessions).

Total, $n$ (SD) (Range: 0-10 sessions)

Home work time (min)
$7.08(1.58)$

$14.0(56.0)$

$1.68(0.63)$

$8.76(2.05)$

$1202.2(455.5)$ 
and in WHO-HPQ absolute presentism at 2 months (Table 7). For the MAIA subscales, there were significant improvements in Noticing, Not-worrying, Attention regulation, Emotional awareness, Self-regulation, Body listening, and Trusting at 4 weeks, and in Not-distracting at 8 weeks (Table 7). No significant differences were found for SPANE-N, SPANEB, GAD, QIDS, EQ-5D-5L utility, or WHO-HPQ relative presentism (Tables 6, 7).

\section{DISCUSSION \\ Overall Results}

This is the first RCT of MBCT to feature a 2-month followup and to target the cognitive and affective aspects of SWB and eudaimonic well-being in community residents. Treatment adherence was high, and the absence of adverse events indicates the favorable feasibility of the program. In terms of the demographics of the participants, a higher proportion of participants were female, a general trend in other MBI studies (de Vibe et al., 2012).

Cognitive aspect of SWB score significantly improved by the end of the 8-week intervention. After 2 months' followup, the cognitive aspect of SWB improvement was further enhanced, and positive affect and eudaimonic well-being had also significantly improved.
For the secondary outcomes, most MAIA subscales showed significant improvements as early as 4 weeks. Previous research has shown that mind-body interventions increase awareness for interception (Bornemann et al., 2015) and awareness of interception is linked to mindfulness abilities (Hanley et al., 2017). Furthermore, it has been theoretically proposed that improved awareness of interception is the basis for metacognitive abilities fostered by mindfulness training (Garland et al., 2015). The present study's finding of significant improvements in awareness of interception followed by improvement of mindfulness skills accords with this suggestion. At 8 weeks, there was a significant improvement in mindfulness abilities and selfcompassion, both of which are considered to be elements of the mindfulness mechanism (Kuyken et al., 2010; Gu et al., 2015). Further, resilience, self-esteem, and work productivity significantly improved at 16 weeks. This indicates that intensive mindfulness training can improve a variety of health outcomes, even with a reduced frequency of intervention after 8 weeks.

There was no significant improvement in some outcomes. In particular, anxiety and negative affect that were demonstrated to be improved by MBIs did not improve in the study (Schumer et al., 2018) (Ninomiya et al., 2019). In a study of Japanese undergraduate students, the mean score (SD) of the SPANE-N was 16.61 (4.87) (Sumi, 2014), which was similar to the results of the present study. Similarly, the mean score (SD) of the general population for GAD7 was 2.95 (3.41) (Löwe et al., 2008),

TABLE 6 | Effects of repeated-measure analyses of well-being outcomes (intention-to-treat population).

\begin{tabular}{|c|c|c|c|c|c|c|c|c|c|}
\hline \multirow[t]{2}{*}{ Measures } & \multirow[t]{2}{*}{ Time points } & \multicolumn{2}{|c|}{$\begin{array}{l}\text { MBCT } \\
(n=25)\end{array}$} & \multicolumn{2}{|c|}{$\begin{array}{l}\text { Control } \\
(n=25)\end{array}$} & \multicolumn{2}{|c|}{$\begin{array}{l}\text { Difference in mean change scores } \\
\qquad(95 \% \mathrm{Cl})\end{array}$} & \multirow[t]{2}{*}{$P$ Value } & \multirow[t]{2}{*}{ Effect size } \\
\hline & & Mean & SD & Mean & SD & & & & \\
\hline \multirow[t]{4}{*}{ SWLS } & Baseline & 18.7 & 4.2 & 18.3 & 4.5 & & & & \\
\hline & $4-w k$ & 21.0 & 4.4 & 19.5 & 5.4 & 0.90 & (-1.49 to 3.28$)$ & 0.46 & 0.21 \\
\hline & $8-w k$ & 22.8 & 5.3 & 19.6 & 5.9 & 2.79 & (0.39 to 5.20$)$ & 0.02 & 0.47 \\
\hline & 2-mo follow-up & 24.3 & 4.9 & 20.5 & 5.4 & 3.38 & (0.94 to 5.81$)$ & 0.007 & 0.55 \\
\hline \multirow[t]{4}{*}{ FS } & Baseline & 40.6 & 5.1 & 37.5 & 6.5 & & & & \\
\hline & $4-w k$ & 42.4 & 5.1 & 37.1 & 7.4 & 2.07 & $(-0.45$ to 4.60$)$ & 0.11 & 0.63 \\
\hline & $8-w k$ & 43.2 & 5.3 & 38.7 & 5.3 & 1.39 & $(-1.15$ to 3.93$)$ & 0.28 & 0.57 \\
\hline & 2-mo follow-up & 45.0 & 7.2 & 38.4 & 5.6 & 3.56 & (0.98 to 6.14) & 0.007 & 0.81 \\
\hline \multirow[t]{4}{*}{ SPANE-P } & Baseline & 21.3 & 2.8 & 18.8 & 2.8 & & & & \\
\hline & $4-w k$ & 22.8 & 2.7 & 20.0 & 3.2 & 0.08 & $(-1.57$ to 1.73$)$ & 0.92 & 0.78 \\
\hline & $8-w k$ & 23.1 & 3.0 & 19.3 & 3.1 & 1.24 & $(-0.41$ to 2.90$)$ & 0.14 & 0.96 \\
\hline & 2-mo follow-up & 24.4 & 3.3 & 19.1 & 3.4 & 2.89 & (1.21 to 4.57$)$ & 0.001 & 1.33 \\
\hline \multirow[t]{4}{*}{ SPANE-N } & Baseline & 17.0 & 3.6 & 18.6 & 2.9 & & & & \\
\hline & $4-w k$ & 15.2 & 3.6 & 17.0 & 4.2 & -0.40 & $(-2.41$ to 1.60$)$ & 0.70 & 0.39 \\
\hline & $8-w k$ & 15.4 & 4.3 & 17.8 & 3.5 & -1.04 & $(-3.06$ to 0.97$)$ & 0.31 & 0.50 \\
\hline & 2-mo follow-up & 15.7 & 4.5 & 17.1 & 3.6 & -0.08 & $(-2.13$ to 1.96$)$ & 0.94 & 0.31 \\
\hline \multirow[t]{4}{*}{ SPANE-B } & Baseline & 4.3 & 5.4 & 0.2 & 3.6 & & & & \\
\hline & 4-wk & 7.6 & 5.1 & 3.0 & 6.1 & 0.47 & (-2.59 to 3.52$)$ & 0.76 & 0.65 \\
\hline & $8-w k$ & 7.7 & 6.3 & 1.5 & 5.6 & 2.27 & $(-0.81$ to 5.34$)$ & 0.15 & 0.86 \\
\hline & 2-mo follow-up & 8.7 & 7.0 & 2.0 & 5.9 & 2.95 & $(-0.16$ to 6.07$)$ & 0.06 & 0.91 \\
\hline
\end{tabular}

FS, Flourishing Scale; SPANE, Scale of Positive and Negative Experience; SWLS, Satisfaction With Life Scale. 
TABLE 7 | Summary of repeated-measure analyses of other outcomes (intention-to-treat population).

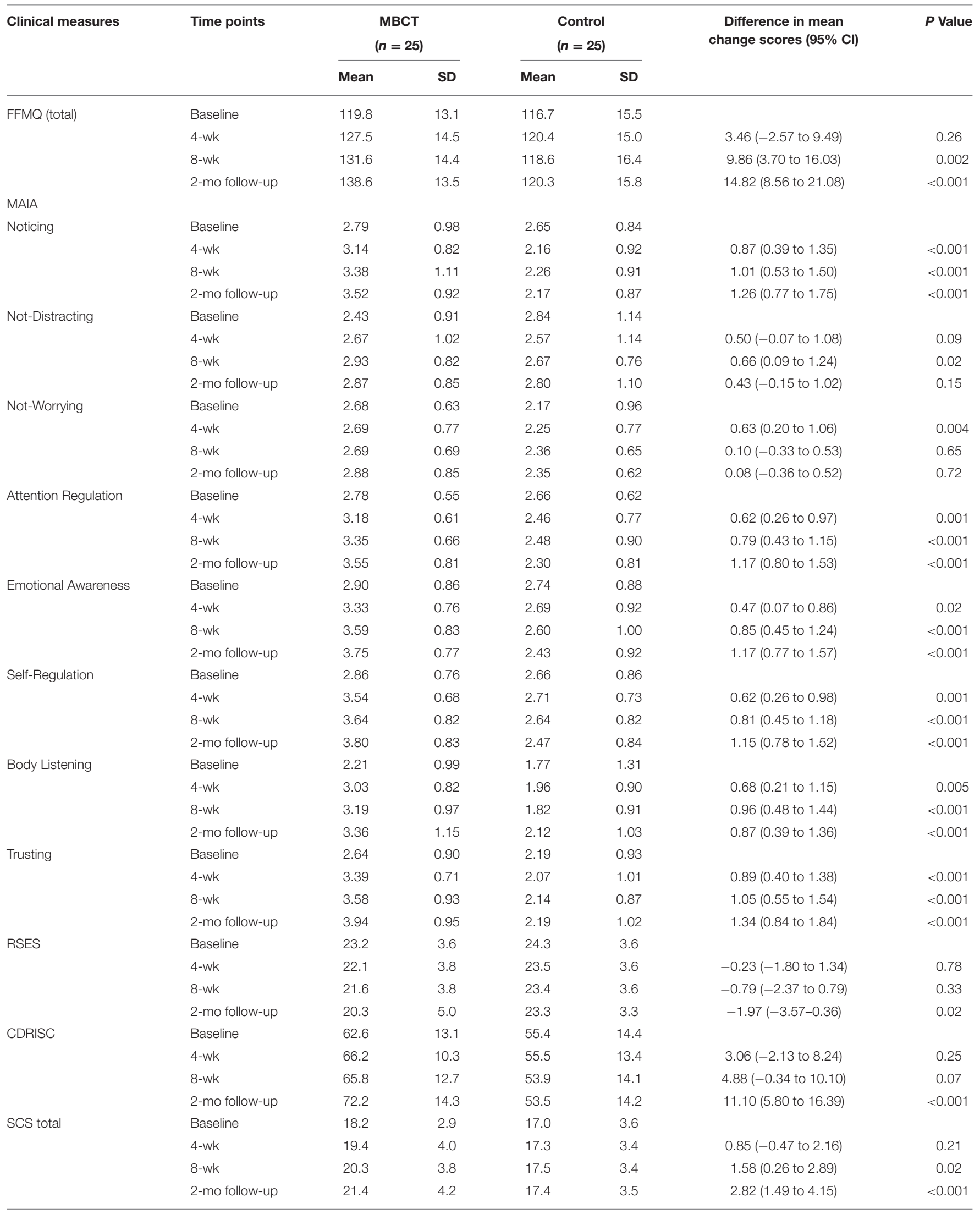


TABLE 7 | Continued

\begin{tabular}{|c|c|c|c|c|c|c|c|}
\hline \multirow[t]{2}{*}{ Clinical measures } & \multirow[t]{2}{*}{ Time points } & \multicolumn{2}{|c|}{$\begin{array}{c}\text { МBCT } \\
(n=25)\end{array}$} & \multicolumn{2}{|c|}{$\begin{array}{l}\text { Control } \\
(n=25)\end{array}$} & \multirow[t]{2}{*}{$\begin{array}{c}\text { Difference in mean } \\
\text { change scores }(95 \% \mathrm{Cl})\end{array}$} & \multirow[t]{2}{*}{$P$ Value } \\
\hline & & Mean & SD & Mean & SD & & \\
\hline \multirow[t]{3}{*}{ PSS } & Baseline & 16.8 & 3.9 & 18.8 & 4.1 & & \\
\hline & 4-wk & 15.4 & 3.1 & 17.9 & 4.0 & $-0.09(-2.47$ to 2.30$)$ & 0.94 \\
\hline & 8-wk & 13.9 & 4.7 & 19.7 & 5.3 & $-3.46(-5.86-1.06)$ & 0.005 \\
\hline \multirow[t]{4}{*}{ GAD7 } & Baseline & 4.2 & 3.4 & 4.3 & 2.9 & & \\
\hline & 4-wk & 2.6 & 2.1 & 3.5 & 3.1 & $-0.77(-2.31$ to 0.77$)$ & 0.33 \\
\hline & 8-wk & 2.5 & 2.6 & 4.0 & 3.6 & $-1.35(-2.90$ to 0.19$)$ & 0.09 \\
\hline & 2-mo follow-up & 2.3 & 3.0 & 3.2 & 2.0 & $-0.67(-2.24$ to 0.89$)$ & 0.40 \\
\hline QIDS & Baseline & 3.6 & 2.5 & 4.0 & 3.5 & & \\
\hline \multirow{3}{*}{ EQ-5D-5L utility } & 4-wk & 0.92 & 0.11 & 0.86 & 0.12 & $0.02(-0.05$ to 0.08$)$ & 0.63 \\
\hline & 8-wk & 0.94 & 0.10 & 0.87 & 0.11 & $0.03(-0.03$ to 0.10$)$ & 0.32 \\
\hline & 2-mo follow-up & 0.95 & 0.09 & 0.91 & 0.12 & $0.01(-0.06$ to 0.07$)$ & 0.85 \\
\hline WHO-HPQ & Baseline & 60.0 & 20.0 & 56.5 & 16.4 & & \\
\hline \multirow[t]{3}{*}{ (absolute presenteeism) } & 4-wk & 71.7 & 18.5 & 60.4 & 15.8 & $7.01(-3.16$ to 17.19$)$ & 0.18 \\
\hline & 8-wk & 71.4 & 18.3 & 58.8 & 16.2 & 9.26 (-0.91 to 19.44$)$ & 0.07 \\
\hline & 2-mo follow-up & 74.5 & 20.2 & 56.5 & 13.0 & 12.93 (2.65 to 23.21$)$ & 0.01 \\
\hline WHO-HPQ & Baseline & 0.98 & 0.25 & 1.06 & 0.27 & & \\
\hline \multirow[t]{2}{*}{ (relative presenteeism) } & 4-wk & 1.07 & 0.35 & 1.12 & 0.33 & $0.04(-0.15$ to 0.24$)$ & 0.66 \\
\hline & 8-wk & 1.05 & 0.20 & 1.05 & 0.29 & $0.06(-0.14$ to 0.26$)$ & 0.53 \\
\hline
\end{tabular}

CD-RISC, the Connor-Davidson Resilience Scale; EQ-5D-5L, Five level EuroQoL-5 Dimensions; FFMQ, Five Facet Mindfulness Scale; GAD7, Generalized Anxiety Disorder Questionnaire; MAIA, The Multidimensional Assessment of Interoceptive Awareness; PSS, Perceived Stress Scale; QIDS, Quick Inventory of Depressive Symptomatology; RSES, Rosenberg Self Esteem Scale; SCS, Self-Compassion Scale; WHO-HPQ, The World Health Organization Heath and Work Performance Questionnaire.

which was similar to the score of the participants in the present study. Therefore, the participants in the study were mentally healthy individuals with low baseline anxiety and negative affect scores, which led to our inability to detect statistically significant improvement in the scales after the intervention.

\section{Relationship Between Mindfulness and Subjective Well-Being}

Garland et al. (2015) proposed a mindfulness-to-meaning theory that explains the mechanism of the effect of mindfulness on well-being (Garland et al., 2015). This theory suggests that mindfulness practice increases metacognitive capacity for experience by improving mindfulness skills. This releases habitual perceptions of the experience, which leads to a broadening of recognition and a reconstruction of the experience. This results in a positive reappraisal of the experience and an increase in positive affect. Positive affect is linked to meaning in life through the recognition of experiences broadened by mindfulness training, which results in enhancing eudaimonic well-being. According to this theory, the order of improvement should be mindfulness skill, followed by the cognitive, affective, and eudaimonic well-being, respectively.

Interestingly, the temporal order in which mindfulness skill and each type of well-being improved in the study (i.e., the mindfulness skill and cognitive aspect of SWB after 8 weeks, followed by the affective aspects of SWB and eudaimonic wellbeing at 16 weeks) paralleled the order of improvement shown in the theory. Although more detailed research is needed, the framework of the theory could potentially explain the mechanisms by which each aspect of well-being improves.

\section{Clinical Implications}

This study highlights a means of improving SWB and eudaimonic well-being among healthy individuals. Mindfulness is a "static" and "reflecting" intervention; therefore, it may represent a desirable option for people who do not prefer "activating" interventions (e.g., exercise, behavior activation).

\section{Limitations}

First, the follow-up period, 2 months after the intervention, was relatively short. Second, although the participants were recruited from the community, because this was a single-center 
study with small samples, they didn't necessarily represent the characteristics of the whole population. Finally, the control group was a waiting group. Thus, we cannot exclude the influence of non-specific intervention effects. Future studies should include multi-center RCTs for more diverse community residents with active control groups and longer follow-up periods.

\section{CONCLUSIONS}

In conclusion, we found that 8 weeks of MBCT with a 2month follow-up period improves cognitive and affective aspects of subjective and eudaimonic well-being in healthy individuals. The order of improvement was cognitive, positive affective, and eudaimonic, respectively. Future studies should conduct multi-center RCTs with active control groups and longer followup periods.

\section{DATA AVAILABILITY STATEMENT}

The datasets presented in this article are not readily available because according to the ethics committee's rules, the Ethics Review Committee of the Keio University School of Medicine will review the request for release of the research data and, if permitted, we disclose it. Requests to access the datasets should be directed to Mitsuhiro Sado, mitsusado@keio.jp.

\section{ETHICS STATEMENT}

The studies involving human participants were reviewed and approved by the Ethics Review Committee of the Keio University School of Medicine. The participants provided their written informed consent to participate in this study.

\section{REFERENCES}

American Psychiatric Association (2000). Diagnostical and Statistical Manual of Mental Disorders (DSM-IV-TR). Washington, DC: American Psychiatric Association.

Arimitsu, K. (2014). Development and validation of the Japanese version of the Self-Compassion Scale. Japan. J. Psychol. 85, 50-59 (in Japanese). doi: 10.4992/jjpsy.85.50

Baer, R. A., Smith, G. T., Hopkins, J., Krietemeyer, J., and Toney, L. (2006). Using self-report assessment methods to explore facets of mindfulness. Assessment 13, 27-45. doi: 10.1177/1073191105283504

Bartlett, L., Lovell, P., Otahal, P., and Sanderson, K. (2017). Acceptability, Feasibility, and efficacy of a workplace mindfulness program for public sector employees: a pilot randomized controlled trial with informant reports. MIndfulness 8, 639-654. doi: 10.1007/s12671-016-0643-4

Bolier, L., Haverman, M., Westerhof, G. J., Riper, H., Smit, F., and Bohlmeijer, E. (2013). Positive psychology interventions: a meta-analysis of randomized controlled studies. BMC Public Health 13:119. doi: 10.1186/1471-2458-13-119

Bornemann, B., Herbert, B. M., Mehling, W. E., and Singer, T. (2015). Differential changes in self-reported aspects of interoceptive awareness through 3 months of contemplative training. Front. Psychol. 5:1504. doi: 10.3389/fpsyg.2014.01504

Buchanan, K. E., and Bardi, A. (2010). Acts of kindness and acts of novelty affect life satisfaction. J. Soc. Psychol. 150, 235-237. doi: 10.1080/00224540903365554

Burton, C. M., and King, L. A. (2004). The health benefits of writing about intensely positive experiences. J. Res. Pers. 38, 150-163. doi: 10.1016/S0092-6566(03)00058-8

\section{AUTHOR CONTRIBUTIONS}

TK: Conceptualization, Data curation, Formal analysis, Investigation, Methodology, Project administration, Visualization, Writing-original draft, and Writing-review and editing. AN: Conceptualization, Data curation, Formal analysis, Investigation, Methodology, Project administration, Writing-original draft, and Writing - review and editing. MN: Investigation, Writing-review, and editing. ZH: Investigation and Writing-review and editing. KS: Investigation and Writing-review and editing. SP and DF: Conceptualization and Writing-review and editing. MM: Conceptualization, Supervision, and Writing-review and editing. MS: Conceptualization, Investigation, Methodology, Project administration, Supervision, Writing — original draft, Writingreview and editing, and Funding acquisition. All authors contributed to the article and approved the submitted version.

\section{FUNDING}

This study was funded by Grant-in-Aid for Scientific Research $<$ KAKENHI $>$ of the Japanese Ministry of Education, Culture, Sport, Science, and Technology [grant number: 16K08881; URL: https://www.jsps.go.jp/english/e-grants/] to the corresponding author.

\section{ACKNOWLEDGMENTS}

We would like to thank Dr. Yasunori Sato for advice on statistical analysis, Ms. Ayaka Inaba and Ms. Naho Goto for their remarkable assistance in managing the study and developing the dataset, and Editage for English-language editing.

Carmody, J., and Baer, R. A. (2008). Relationships between mindfulness practice and levels of mindfulness, medical and psychological symptoms and well-being in a mindfulness-based stress reduction program. J. Behav. Med. 31, 23-33. doi: $10.1007 /$ s10865-007-9130-7

Chu, S. T. W., and Mak, W. W. S. (2020). How mindfulness enhances meaning in life: a meta-analysis of correlational studies and randomized controlled trials. Mindfulness 11, 177-193. doi: 10.1007/s12671-019-01258-9

Cohen, S., Kamarck, T., and Mermelstein, R. (1983). A global measure of perceived stress. J. Health Soc. Behav. 24, 385-396. doi: 10.2307/213 6404

Cohen-Katz, J., Wiley, S. D., Capuano, T., Baker, D. M., Kimmel, S., and Shapiro, S. (2005). The effects of mindfulness-based stress reduction on nurse stress and burnout, Part II: a quantitative and qualitative study. Holist. Nurs. Pract. 19, 26-35. doi: 10.1097/00004650-200501000-00008

Connor, K. M., and Davidson, J. R. (2003). Development of a new resilience scale: the Connor-Davidson Resilience Scale (CD-RISC). Depress. Anxiety 18, 76-82. doi: 10.1002/da. 10113

Crane, R. S., Brewer, J., Feldman, C., Kabat-Zinn, J., Santorelli, S., Williams, J. M., et al. (2017). What defines mindfulness-based programs? the warp and the weft. Psychol. Med. 47, 990-999. doi: 10.1017/S00332917160 03317

de Vibe, M., Bjørndal, A., Tipton, E., Hammerstrøm, K., and Kowalski, K. (2012). Mindfulness based stress reduction (MBSR) for improving health, quality of life, and social functioning in Adults. Campbell Syst. Rev. 8, 1-127 doi: $10.4073 /$ csr.2012.3 
de Vibe, M., Solhaug, I., Tyssen, R., Friborg, O., Rosenvinge, J. H., Sorlie, T., et al. (2013). Mindfulness training for stress management: a randomised controlled study of medical and psychology students. BMC Med. Educ. 13:107. doi: 10.1186/1472-6920-13-107

Diener, E. (1984). Subjective well-being. Psychol. Bull. 95, 542-575. doi: 10.1037/0033-2909.95.3.542

Diener, E., and Chan, M. (2011). Happy people live longer: subjective wellbeing contributes to health and longevity Well-Being. Psychology 4:2001. doi: 10.1037/e675972011-001

Diener, E., Emmons, R. A., Larsen, R. J., and Griffin, S. (1985). The satisfaction with life scale. J. Pers. Assess. 49, 71-75. doi: 10.1207/s15327752jpa4901_13

Diener, E., Lucas, R. E., and Oishi, S. (2018). Advances and open questions in the science of subjective well being. Physology 4:15. doi: 10.1525/collabra.115

Diener, E., Pressman, S. D., Hunter, J., and Delgadillo-Chase, D. (2017). If, why, and when subjective well-being influences health, and future needed research. Appl. Psychol. Health Well Being 9, 133-167. doi: 10.1111/aphw.12090

Diener, E., Tov, W., Kim-Prieto, C., Choi, D., Oishi, S., and BiswasDiener, R. (2010). New well-being measures: short scales to assess flourishing and positive and negative feelings. Soc. Indic. Res. 97, 143-156. doi: 10.1007/s11205-009-9493-y

Doi, S., Ito, M., Takebayashi, Y., Muramatsu, K., and Horikoshi, M. (2018). Factorial Validity and Invariance of the 7-Item Generalized Anxiety Disorder Scale (GAD-7) Among Populations With and Without Self-Reported Psychiatric Diagnostic Status. Front. Psychol. 9:1741. doi: 10.3389/fpsyg.2018.01741

Flook, L., Goldberg, S. B., Pinger, L., Bonus, K., and Davidson, R. J. (2013). Mindfulness for teachers: a pilot study to assess effects on stress, burnout and teaching efficacy. Mind Brain Educ. 7:12026. doi: 10.1111/mbe.12026

Foley, E., Baillie, A., Huxter, M., Price, M., and Sinclair, E. (2010). Mindfulnessbased cognitive therapy for individuals whose lives have been affected by cancer: a randomized controlled trial. J. Consult. Clin. Psychol. 78, 72-79. doi: $10.1037 / \mathrm{a} 0017566$

Fujisawa, D., Nakagawa, A., Tajima, M., Sado, M., Kikuchi, T., and Iba, M. (2010). Cross-cultural adaptation of the Quick inventory of depressive symptomatology, self-report (QIDS-SR). Japan. J. Stress Sci. 25, 43-52 (in Japanese).

Garland, E. L., Farb, N. A., Goldin, P. R., and Fredrickson, B. L. (2015). Mindfulness broadens awareness and builds eudaimonic meaning: a process model of mindful positive emotion regulation. Psychol. Inq. 26, 293-314. doi: 10.1080/1047840X.2015.1064294

Gu, J., Strauss, C., Bond, R., and Cavanagh, K. (2015). How do mindfulnessbased cognitive therapy and mindfulness-based stress reduction improve mental health and wellbeing? a systematic review and meta-analysis of mediation studies. Clinic. Psychol. Rev. 37, 1-12. doi: 10.1016/j.cpr.2015. 01.006

Hamashima, C., and Yoshida, K. (2001). A study of the reliability of health state valuations in the Japanese EuroQol instrument. Environ. Health Prev. Med. 6, 189-191. doi: 10.1007/BF02897969

Hanley, A. W., Mehling, W. E., and Garland, E. L. (2017). Holding the body in mind: Interoceptive awareness, dispositional mindfulness and psychological well-being. J. Psychosom. Res. 99, 13-20. doi: 10.1016/j.jpsychores.2017.05.014

Herdman, M., Gudex, C., Lloyd, A., Janssen, M. F., Kind, P., Parkin, D., et al. (2011). Development and preliminary testing of the new fivelevel version of EQ-5D (EQ-5D-5L). Qual. Life Res. 20, 1727-1736. doi: 10.1007/s11136-011-9903-x

Hoge, E. A., Bui, E., Marques, L., Metcalf, C. A., Morris, L. K., Robinaugh, D. J., et al. (2013). Randomized controlled trial of mindfulness meditation for generalized anxiety disorder: effects on anxiety and stress reactivity. J. Clin. Psychiatry 74, 786-792. doi: 10.4088/JCP.12m08083

Howell, R. T., Kern, M. L., and Lyubomirsky, S. (2007). Health benefits: Metaanalytically determining the impact of well-being on objective health outcomes. Health Psychol. Rev. 1, 83-136. doi: 10.1080/17437190701492486

Huang, S. L., Li, R. H., Huang, F. Y., and Tang, F. C. (2015). The Potential for Mindfulness-based intervention in workplace mental health promotion: results of a randomized controlled trial. PLOS ONE 10:e138089. doi: 10.1371/journal.pone.0138089

Huppert, F. A., Marks, N., Clark, A., Siegrist, J., Stutzer, A., Vitters,ø, J., et al. (2009). Measuring well-being across europe: description of the ess well-being module and preliminary findings. Soc. Indic. Res. 91, 301-315 doi: 10.1007/s11205-008-9346-0

Ito, M., Nakajima, S., Shirai, A., and Kim, Y. (2009). "Reliability and validity of Japanese version Conner Davidson resilience scale: Consideration for general adults and university students", in 20th Annual Report Meeting of National Institute of Mental Health, National Center of Neurology and Psychiatry (Tokyo: National Center of Neurology and Psychiatry).

Ivtzan, I., Young, T., Lee, H. C., Lomas, T., Daukantait,e, D., and Kjell, O. N. E. (2018). Mindfulness based flourishing program: a cross-cultural study of Hong Kong Chinese and British participants. J. Happiness Stud. Interdisciplin. Forum Subject. Well-Being 19, 2205-2223. doi: 10.1007/s10902-017-9919-1

Ivtzan, I., Young, T., Martman, J., Jeffrey, A., Lomas, T., Hart, R., et al. (2016). Integrating mindfulness into positive psychology: a randomised controlled trial of an online positive mindfulness program. Mindfulness 7:581. doi: 10.1007/s12671-016-0581-1

Jain, S., Shapiro, S. L., Swanick, S., Roesch, S. C., Mills, P. J., Bell, I., et al. (2007) A randomized controlled trial of mindfulness meditation versus relaxation training: effects on distress, positive states of mind, rumination, and distraction. Ann. Behav. Med. 33, 11-21. doi: 10.1207/s15324796abm3301_2

Kadono, T. (1994). Development and validation of the Japanese version of the Satisfaction With Life Scale Japanese association of educational psychology 36, 192 (in Japanese).

Kawakami, N., Inoue, A., Tsuchiya, M., Watanabe, K., Imamura, K., Iida, M., et al. (2020). Construct validity and test-retest reliability of the World Mental Health Japan version of the World Health Organization Health and Work Performance Questionnaire Short Version: a preliminary study. Ind. Health 58, 375-387. doi: 10.2486/indhealth.2019-0090

Kessler, R. C., Barber, C., Beck, A., Berglund, P., Cleary, P. D., McKenas, D., et al. (2003). The World Health Organization Health and Work Performance Questionnaire (HPQ). J. Occupat. Environ. Med. 45, 156-174. doi: 10.1097/01.jom.0000052967.43131.51

Keyes, C. L., Shmotkin, D., and Ryff, C. D. (2002). Optimizing well-being: the empirical encounter of two traditions. J. Pers. Soc. Psychol. 82, 1007-1022. doi: 10.1037/0022-3514.82.6.1007

Khoury, B., Lecomte, T., Fortin, G., Masse, M., Therien, P., Bouchard, V., et al. (2013). Mindfulness-based therapy: a comprehensive meta-analysis. Clin. Psychol. Rev. 33, 763-771. doi: 10.1016/j.cpr.2013.05.005

Khoury, B., Sharma, M., Rush, S. E., and Fournier, C. (2015). Mindfulness-based stress reduction for healthy individuals: a meta-analysis. J. Psychosom. Res. 78, 519-528. doi: 10.1016/j.jpsychores.2015.03.009

Klatt, M. D., Buckworth, J., and Malarkey, W. B. (2009). Effects of low-dose mindfulness-based stress reduction (MBSR-ld) on working adults. Health Educ. Behav. 36, 601-614. doi: 10.1177/1090198108317627

Kuyken, W., Watkins, E., Holden, E., White, K., Taylor, R. S., Byford, S., et al. (2010). How does mindfulness-based cognitive therapy work? Behav. Res. Ther. 48, 1105-1112. doi: 10.1016/j.brat.2010.08.003

Löwe, B., Decker, O., Müller, S., Brähler, E., Schellberg, D., Herzog, W., et al. (2008). Validation and standardization of the generalized anxiety disorder screener (GAD-7) in the general population. Med. Care 46, 266-274. doi: 10.1097/MLR.0b013e318160d093

Lyubomirsky, S., Dickerhoof, R., Boehm, J. K., and Sheldon, K. M. (2011). Becoming happier takes both a will and a proper way: an experimental longitudinal intervention to boost well-being. Emotion 11, 391-402. doi: $10.1037 / \mathrm{a} 0022575$

Malarkey, W. B., Jarjoura, D., and Klatt, M. (2013). Workplace based mindfulness practice and inflammation: a randomized trial. Brain Behav. Immun. 27, 145-154. doi: 10.1016/j.bbi.2012.10.009

Mehling, W. E., Price, C., Daubenmier, J. J., Acree, M., Bartmess, E., and Stewart, A (2012). The Multidimensional Assessment of Interoceptive Awareness (MAIA) PLoS ONE 7:e48230. doi: 10.1371/journal.pone.0048230

Mimura, C., and Griffiths, P. (2007). A Japanese version of the rosenberg selfesteem scale: translation and equivalence assessment. J. Psychosom. Res. 62, 589-594. doi: 10.1016/j.jpsychores.2006.11.004

Mimura, C., and Griffiths, P. (2008). A Japanese version of the perceived stress scale: cross-cultural translation and equivalence assessment. BMC Psychiatry 8:85. doi: 10.1186/1471-244X-8-85

Muramatsu, K., Miyaoka, H., Ueshima, K., Muramatsu, Y., Fuse, K., Yoshimine, H., et al. (2010). "Validation and utility of a Japanese version of the GAD-7", in: 
The 51th Congress of the Japanese Society of Psychosomatic Medicine. (Sendai, Japan: Tokyo: Miwasyoten).

Muramatsu, K. M.Y., and Miyaoka, H. (2009). "Validation and utility of a Japanese version of the GAD-7", in PANMINERVA MEDICA 20th World Congress on Pyschosomatic Medicine Abstracts Book (Turin: Edizioni Minerva Medica).

Neff, K. D. (2003). The development and validation of a scale to measure selfcompassion. Self Identity 2, 223-250. doi: 10.1080/15298860309027

Ninomiya, A., Sado, M., Park, S., Fujisawa, D., Kosugi, T., Nakagawa, A., et al. (2019). Effectiveness of mindfulness-based cognitive therapy in patients with anxiety disorders in secondary-care settings: a randomized controlled trial. Psychiatry Clin. Neurosci. 74, 132-139. doi: 10.1111/pcn.12960

Nyklicek, I., Mommersteeg, P. M., Van Beugen, S., Ramakers, C., and Van Boxtel, G. J. (2013). Mindfulness-based stress reduction and physiological activity during acute stress: a randomized controlled trial. Health Psychol. 32, 1110-1113. doi: $10.1037 / \mathrm{a} 0032200$

OECD (2013). OECD guidelines on measuring subjective well-being. Paris: OECD Publishing.

Oishi, S. (2009). Science of Happiness: What psychology discovered [Japanese] Shiawase wo kagakusuru: Shinri-gaku kara wakatta koto. Shinyosya.

Robins, C. J., Keng, S. L., Ekblad, A. G., and Brantley, J. G. (2012). Effects of mindfulness-based stress reduction on emotional experience and expression: a randomized controlled trial. J. Clin. Psychol. 68, 117-131. doi: $10.1002 /$ jclp.20857

Rosenberg, M. (1965). Society and the Adolescent Self-Image. Princeton University Press.

Rush, A. J., Trivedi, M. H., Ibrahim, H. M., Carmody, T. J., Arnow, B., Klein, D. N., et al. (2003). The 16-item Quick Inventory of Depressive Symptomatology (QIDS), clinician rating (QIDS-C), and self-report (QIDS-SR): A psychometric evaluation in patients with chronic major depression. Biol. Psychiatry 54, 573-583. doi: 10.1016/S0006-3223(02)01866-8

Ryff, C. D. (2014). Psychological well-being revisited: advances in the science and practice of eudaimonia. Psychother. Psychosom. 83, 10-28. doi: $10.1159 / 000353263$

Sado, M., Kosugi, T., Ninomiya, A., Nagaoka, M., Park, S., Fujisawa, D., et al. (2020). Mindfulness-based cognitive therapy for improving subjective wellbeing among healthy individuals: protocol for a randomized controlled trial. JMIR Res. Protoc. 9:e15892. doi: 10.2196/15892

Schumer, M. C., Lindsay, E. K., and Creswell, J. D. (2018). Brief mindfulness training for negative affectivity: a systematic review and meta-analysis. $J$. Consult. Clin. Psychol. 86, 569-583. doi: 10.1037/ccp0000324

Segal, Z., Williams, J. M., and Teasdale, J. (2002). Mindfulness-Based Cognitive Therapy for Depression. A New Approach to Preventing Relapse. New York, NY: Guilford Publications.

Shapiro, S. L., Astin, J. A., Bishop, S. R., and Cordova, M. (2005). Mindfulnessbased stress reduction for health care professionals: results from a randomized trial. Int. J. Stress Manag. 12, 164-176. doi: 10.1037/1072-5245.12.2.164

Shapiro, S. L., Brown, K. W., Thoresen, C., and Plante, T. G. (2011). The moderation of mindfulness-based stress reduction effects by trait mindfulness: results from a randomized controlled trial. J. Clin. Psychol. 67, 267-277. doi: $10.1002 /$ jclp. 20761

Shapiro, S. L., Schwartz, G. E., and Bonner, G. (1998). Effects of mindfulnessbased stress reduction on medical and premedical students. J. Behav. Med. 21, 581-599. doi: 10.1023/A:1018700829825
Shoji, M., Mehling, W. E., Hautzinger, M., and Herbert, B. M. (2018). Investigating multidimensional interoceptive awareness in a japanese population: validation of the Japanese MAIA-J. Front. Psychol. 9:1855. doi: 10.3389/fpsyg.2018.01855

Song, Y., and Lindquist, R. (2015). Effects of mindfulness-based stress reduction on depression, anxiety, stress and mindfulness in Korean nursing students. Nurse Educ. Today 35, 86-90. doi: 10.1016/j.nedt.2014.06.010

Spitzer, R. L., Kroenke, K., Williams, J. B. W., and Lowe, B. (2006). A brief measure for assessing generalized anxiety disorder-the GAD-7. Arch. Intern. Med. 166, 1092-1097. doi: 10.1001/archinte.166.10.1092

Steptoe, A., Deaton, A., and Stone, A. A. (2015). Subjective wellbeing, health, and ageing. Lancet 385, 640-648. doi: 10.1016/S0140-6736(13)61489-0

Sugiura, Y., Sato, A., Ito, Y., and Murakami, H. (2011). Development and Validation of the Japanese Version of the Five Facet Mindfulness Questionnaire. Mindfulness 3, 85-94. doi: 10.1007/s12671-011-0082-1

Sumi, K. (2014). Reliability and validity of Japanese versions of the flourishing scale and the scale of positive and negative experience. Soc. Indic. Res. 118, 601-615. doi: 10.1007/s11205-013-0432-6

Teasdale, J. D., Segal, Z. V., Williams, J. M. G., Ridgeway, V. A., Soulsby, J. M., and Lau, M. A. (2000). Prevention of relapse/recurrence in major depression by mindfulness-based cognitive therapy. J. Consult. Clin. Psychol. 68, 615-623. doi: 10.1037/0022-006X.68.4.615

Tsuchiya, A., Ikeda, S., Ikegami, N., Nishimura, S., Sakai, I., Fukuda, T., et al. (2002). Estimating an EQ-5D population value set: the case of Japan. Health Econ. 11, 341-353. doi: 10.1002/hec.673

van Dongen, J. M., van Berkel, J., Boot, C. R., Bosmans, J. E., Proper, K. I., Bongers, P. M., et al. (2016). Long-term cost-effectiveness and return-on-investment of a mindfulness-based worksite intervention: results of a randomized controlled trial. J. Occup. Environ. Med. 58, 550-560. doi: 10.1097/JOM.0000000000000736

Vieten, C., and Astin, J. (2008). Effects of a mindfulness-based intervention during pregnancy on prenatal stress and mood: results of a pilot study. Arch. Womens Ment. Health 11, 67-74. doi: 10.1007/s00737-008-0214-3

Williams, M., and Penman, D. (2011). Mindfulness: A Practical Guide to Finding Peace in a Frantic World. London: Piatkus Books.

Conflict of Interest: The authors declare that the research was conducted in the absence of any commercial or financial relationships that could be construed as a potential conflict of interest.

Publisher's Note: All claims expressed in this article are solely those of the authors and do not necessarily represent those of their affiliated organizations, or those of the publisher, the editors and the reviewers. Any product that may be evaluated in this article, or claim that may be made by its manufacturer, is not guaranteed or endorsed by the publisher.

Copyright ( 2021 Kosugi, Ninomiya, Nagaoka, Hashimoto, Sawada, Park, Fujisawa, Mimura and Sado. This is an open-access article distributed under the terms of the Creative Commons Attribution License (CC BY). The use, distribution or reproduction in other forums is permitted, provided the original author(s) and the copyright owner(s) are credited and that the original publication in this journal is cited, in accordance with accepted academic practice. No use, distribution or reproduction is permitted which does not comply with these terms. 